in vivo $34: 2453-2460(2020)$

doi:10.21873/invivo. 12060

\title{
The Effect of Rutin on Experimental Traumatic Brain Injury and Edema in Rats
}

\author{
SAHIN YUCELI ${ }^{1}$, GULCE NAZ YAZICI $^{2}$, RENAD MAMMADOV $^{3}$, \\ HALIS SULEYMAN ${ }^{3}$, MUSTAFA KAYA ${ }^{4}$ and SELCUK OZDOGAN ${ }^{5}$ \\ ${ }^{1}$ Department of Neurosurgery, Neon Hospital, Erzincan, Turkey; \\ ${ }^{2}$ Department of Histology and Embryology, \\ Erzincan Binali Yildirim University School of Medicine, Erzincan, Turkey; \\ ${ }^{3}$ Department of Pharmacology, Erzincan Binali Yildirim University School of Medicine, Erzincan, Turkey; \\ ${ }^{4}$ Department of Neurosurgery, Sakarya Training and Research Hospital, Sakarya, Turkey; \\ ${ }^{5}$ Department of Neurosurgery, Beykent University School of Medicine, Istanbul, Turkey
}

\begin{abstract}
Background/Aim: The aim of the study was to evaluate the effect of rutin, which is a vitamin P1 flavonoid with anti-inflammatory and anti-edema effects, on traumatic brain injury (TBI) and edema in rats. Materials and Methods: Rats were divided into 3 groups as sham group without brain trauma (SG), brain trauma without medication (BT) group and Rutin treated brain trauma (RBT) group. Fifty $\mathrm{mg} / \mathrm{kg}$ rutin was administered to the RBT group once a day for three days. On the fourth day, rats were sacrificed. Extracted brain tissues were examined biochemically and histopathologically. Results: We found that the levels of malondialdehyde, nuclear factorkappa $B$ and tumor necrosis factor-alpha decreased, and those of total glutathione increased significantly. Furthermore, rutin administration reduced pyramidal neuron degeneration and poly-morpho-nuclear-leucocyte accumulation due to trauma in brain tissue, while eliminating edema. Conclusion: Rutin might be effective in the treatment of TBI and TBI-related brain edema.
\end{abstract}

Traumatic brain injury (TBI) is an important public health problem that can be associated with mortality and disability (1). TBI is an important public health problem in the United States with an annual incidence of approximately 1.7 million, of which 50,000 injuries result in death (2). According to the

This article is freely accessible online.

Correspondence to: Selcuk Ozdogan, MD, Ph.D., Department of Neurosurgery, Beykent University School of Medicine, Beykent Universitesi Tıp Fakultesi Beyin Cerrahisi Anabilim Dalı, 34000 Beylikduzu/Istanbul, Turkey. Tel: +90 5067637173, e-mail: selcukozdogan@beykent.edu.tr

Key Words: Traumatic brain injury, rutin, brain edema. literature, the incidence of TBI is estimated to be 939 cases per 100,000 individuals (3).

TBI occurs as a result of various mechanical traumas due traffic accidents and falls (4). TBI can be classified as primary and secondary damage. Primary TBI occurs after impact. In the primary TBI phase, contusions, rupture of blood vessels, and intracranial hemorrhage constitute ongoing brain damage (5). Secondary TBI occurs a few seconds after the primary injury. This phase is characterized by neuroflamation, oxidative stress, and increased intracranial pressure due to brain edema (6). Niu $\mathrm{X}$ et al. have demonstrated the role of tumor necrosis factor alpha (TNF- $\alpha$ ) and other proinflammatory cytokines in the pathogenesis of TBI. In addition, increased free oxygen radical (FOR) and malondialdehyde (MDA) production and decreased glutathione peroxidase (Gpx), glutathione (GSH) and superoxide dismutase (SOD) levels have been associated with TBI (7). Nuclear factor kappa B (NF-kB) is also known to mediate the transcription of inflammatory genes in TBI (8). Furthermore, it has been reported that NF- $\mathrm{KB}$ is responsible for brain edema developing in TBI (9). All this information suggests that antioxidant, anti-inflammatory and anti-edema factors might be useful for the treatment of TBI and TBIrelated brain edema (TBIE).

In this study, we investigated the effect of rutin $(3,3,4,5,7-$ pentahydroxyflavone-3-rhamnoglucoside), a vitamin P1 flavonoid, against TBI in rats (10). Rutin has been found to be effective against edema that develops as a result of increased capillary permeability and plasma leakage into tissue (11). It has been demonstrated that rutin suppresses the production of NF$\mathrm{kB}$ and TNF- $\alpha$, two proinflammatory factors (12), indicating that rutin can be useful in preventing TBIE development. However, no studies have investigated the effect of rutin on brain injury and edema induced by mechanical trauma in rats. Therefore, the aim of this study was to evaluate the effect of rutin on TBI in rats biochemically and histopathologically. 


\section{Materials and Methods}

Rats were obtained from the Ataturk University Medical Experimental Application and Research Center. Eighteen male albino Wistar rats weighing 285-296 grams were used in the experiment. The animals were fed and kept for one week at room temperature $\left(22^{\circ} \mathrm{C}\right.$, pressure of $1 \mathrm{~atm}$ ) for adaptation to the environment. After one week, the experiment was performed on. The procedures and protocols were approved by the Ataturk University Animal Experimentation Ethics Committee (Date: 28.03.2019 Meeting No:4).

Chemicals. Ketamin was obtained from Pfizer (Istanbul, Turkey) and Rutin was obtained from Solgar (Leonia, NJ, USA).

Experimental groups. Rats were divided into three groups: Sham group (SG) with no trauma or medication, mechanical brain trauma (BT) group, and $50 \mathrm{mg} / \mathrm{kg}$ rutin administered mechanical brain trauma (RBT) group.

Experimental procedure. Surgical procedures were performed under sterile conditions in an appropriate laboratory environment. The Marmarou's impact acceleration model was modified and used to create the brain trauma model (13). In this model, a cylindrical tube with an inner diameter of $18 \mathrm{~mm}$ and an outer diameter of $19 \mathrm{~mm}$ was used. Ketamine hydrochloride was administered intraperitoneally at a dose of $60 \mathrm{mg} / \mathrm{kg}$ to the rats. Subsequently, rats were placed in prone position on cork blocks. In order to prevent collapse fractures in the skull, a $10 \mathrm{~mm}$-diameter and $3 \mathrm{~mm}$-thick steel disc was inserted following skin incision between the coronal and lamdoid sutures. Head trauma was created by applying a mass of $300 \mathrm{~g}$ via free fall from a height of one meter. BT group and SG group were orally administered with $0.5 \mathrm{ml}$ normal saline $(0.9 \%$ $\mathrm{NaCl}$ ) as solvent. Fifty $\mathrm{mg} / \mathrm{kg}$ rutin was administered orally to the RBT group. Rutin and distilled water were administered once a day for three days. Animals were fed with standard rat feed, each in a separate cage at an appropriate environment and room temperature $\left(22^{\circ} \mathrm{C}\right)$. On the fourth day, rats were sacrificed by high-dose ketamine $(120 \mathrm{mg} / \mathrm{kg})$ anesthesia and brain tissues were removed. MDA, tGSH, NF-kB, and TNF- $\alpha$ levels were measured in the extracted brain tissues. Brain tissues were also examined histopathologically.

MDA analysis. Tissue samples were placed in $2 \mathrm{ml} 1.15 \%$ potassium chloride solution for MDA analysis or in $\mathrm{pH}=7.5$ phosphate buffer for other measurements and homogenized on ice. Then, the homogenates were centrifuged at $+4^{\circ} \mathrm{C}$ for $10 \mathrm{~min}$ at 9000 $\times g$. The supernatants were used for the analysis.

MDA levels were measured according to the Ohkawa $\mathrm{H}$ et al. method (14). This method is based on the spectrophotometric measurement (at $532 \mathrm{~nm}$ ) of the absorbance of the pink colored complex formed by thiobarbituric acid (TBA) and MDA at high temperature $\left(95^{\circ} \mathrm{C}\right)$. The homogenates were centrifuged at $5000 \times g$ for $20 \mathrm{~min}$ and these supernatants were used to quantify MDA. One hunderd $\mu \mathrm{l}$ of $8 \%$ sodium dodecyl sulfate (SDS), $250 \mu \mathrm{l}$ of homogenate, $750 \mu \mathrm{l}$ of $20 \%$ acetic acid, $750 \mu \mathrm{l}$ of $0.08 \%$ TBA and $150 \mu \mathrm{l}$ of pure water were pipetted into capped tubes and vortexed. The mixture was incubated at $100^{\circ} \mathrm{C}$ for $60 \mathrm{~min}$, and then $2.5 \mathrm{ml}$ of n-butanol were added and spectrophotometrically measured. The resulting red color was measured using $3 \mathrm{ml}$ cuvettes at $532 \mathrm{~nm}$ and the MDA levels were determined by using a standard curve generated using various concentrations of MDA.
tGSH analysis. DTNB [5,5'-Dithiobis (2-nitrobenzoic acid)] in the measuring medium is a disulfide chromogen and is easily reduced by compounds with sulfhydryl groups. The resulting yellow color was measured spectrophotometrically at $412 \mathrm{~nm} \mathrm{(15).} \mathrm{The}$ homogenates were centrifuged at $12,000 \times \mathrm{g}$ for $10 \mathrm{~min}$ and the supernatants were used to determine the amount of GSH. $1500 \mu \mathrm{l}$ measuring buffer $(200 \mathrm{mM}$ Tris- $\mathrm{HCl}$ containing $0.2 \mathrm{mM}$ EDTA, $\mathrm{pH}=8.2$ ), $500 \mu \mathrm{l}$ supernatant, $100 \mu \mathrm{l}$ 5,5'-Dithio-bis (2-nitrobenzoic acid) (DTNB), and 7,900 $\mu 1$ methanol were pipetted into capped tubes and vortexed. The mixture was incubated at $37^{\circ} \mathrm{C}$ for $30 \mathrm{~min}$ and then the absorbance was measured at $412 \mathrm{~nm}$. The GSH levels in the samples were determined by using a standard curve generated using various concentrations of GSH.

TNF- $\alpha$ and NF- $\mathrm{K} B$ analysis. Tissue-homogenate TNF- $\alpha$ and NF- $\mathrm{KB}$ concentrations were investigated using rat-specific sandwich enzyme-linked immunosorbent assay Rat Tumor Necrosis Factor $\alpha$ ELISA kit (Cat no: YHB1098Ra, Shanghai LZ, PR China) and Rat Nuclear Factor- Kappa B ELISA immunoassay kit (Cat. No:201-110288, SunRed, Shanghai, PR China). Analyses were performed according to the manufacturers' instructions. Monoclonal antibody specific for rat TNF- $\alpha$ or NF-kB were coated onto the wells of the micro plates. The tissue homogenate, standards and streptavidinHRP and biotinylated monoclonal antibody were pipetted into these wells and then incubated at $37^{\circ} \mathrm{C}$ for $60 \mathrm{~min}$. Following the addition of chromogen A and chromogen B, the samples were incubated at $37^{\circ} \mathrm{C}$ for 10 min to develop the color. Than the stop solution was added. The intensity of the colored product is directly proportional to the concentration of rat TNF- $\alpha$ and NF- $\mathrm{kB}$ present in the original specimen. At the end, the absorbance was measured at $450 \mathrm{~nm}$ and the concentrations of TNF- $\alpha$ and NF-KB were calculated using the corresponding standard curves.

Statistical analysis. Descriptive statistics were used for each group. The results obtained from the experiments were expressed as "mean value \pm standard deviation" $(x \pm S D)$. Outlier analysis was performed using the Tukey test. Differences between groups were compared by one-way analysis of variance (ANOVA). All statistical analyses were performed with "SPSS Statistics Version 18" statistical software (IBM Statistics, USA) and $p$-values $<0.05$ were considered significant.

Histopathological examination. First, all tissue samples were placed in $10 \%$ formaldehyde solution for light-microscope investigation. Then, tissue samples were washed with water for $24 \mathrm{~h}$ and serially treated with increasing concentrations of alcohol $(70 \%, 80 \%, 90 \%$, and $100 \%$ ) to remove water from the tissues. The tissues were incubated with xylol and embedded in paraffin. Forty-five micron sections were cut from the paraffin blocks and were stained with hematoxylin-eosin. The photos were taken using the Olympus DP2SAL microscope (Olympus ${ }^{\circledR}$ Inc. Tokyo, Japan). Histopathological examination was performed blindly by the pathologist .

\section{Results}

MDA and GSH analysis results. While the amount of MDA in brain tissue of the BT group was significantly higher compared to the SG and RBT groups $(p<0.001)$, the amount of tGSH was found to be $(p<0.001)$ (Figure 1). The 

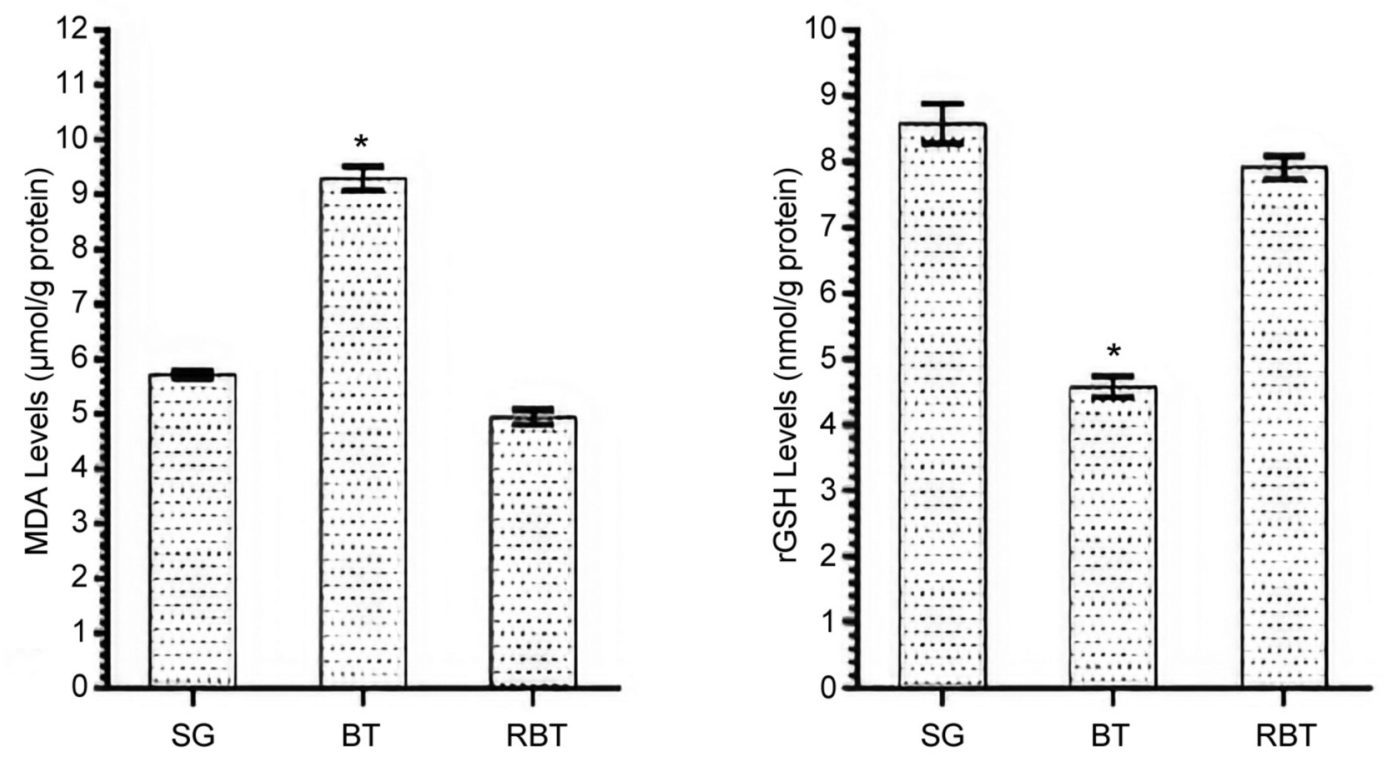

Figure 1. MDA and tGSH levels of $S G, B T$ and RBT groups. * $p<0.0001$ compared to $S G$ and $R B T$ groups $(n=6)$.
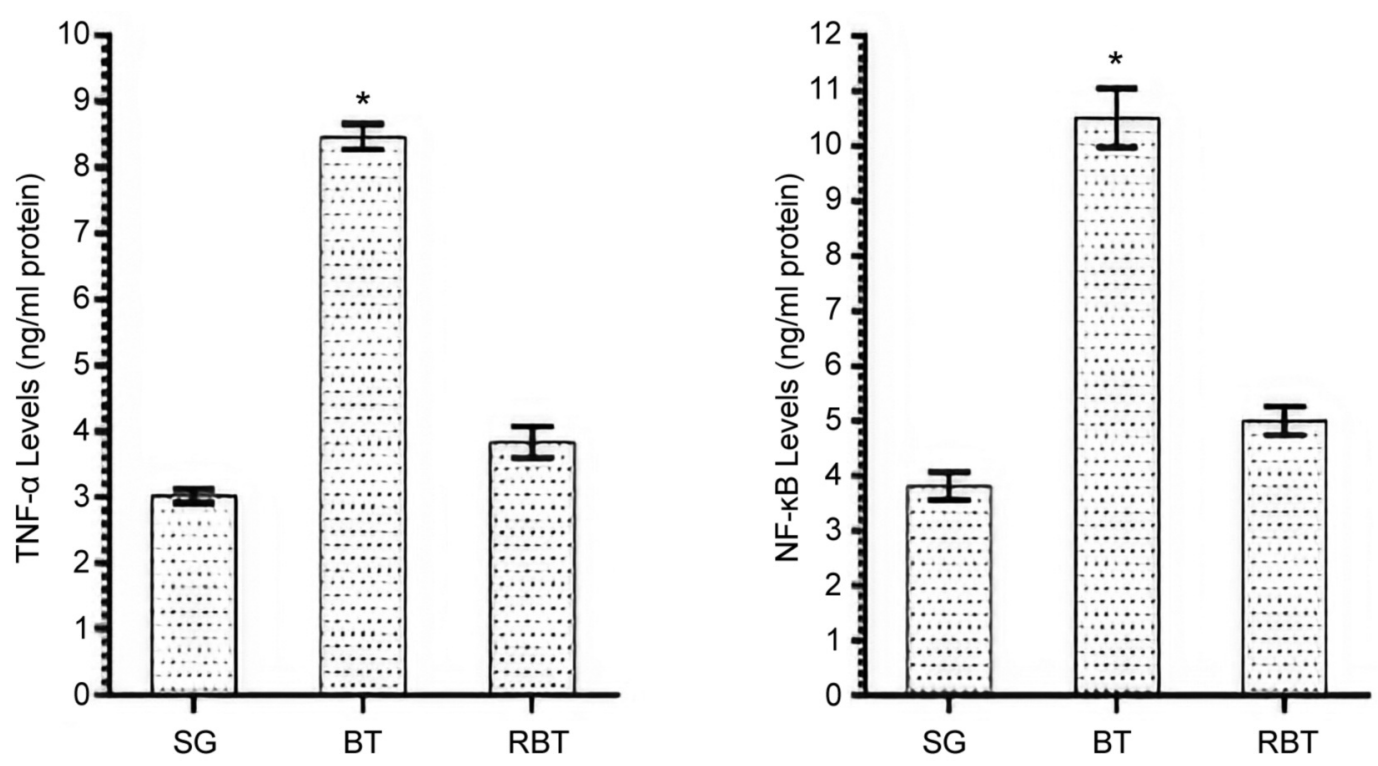

Figure 2. TNF- $\alpha$ and NF- $k B$ levels of $S G, B T$ and RBT groups. ${ }^{*} p<0.0001$ compared to $S G$ and RBT groups $(n=6)$.

difference between the amount of MDA and tGSH in RBT and SG animal groups was statistically insignificant.

$T N F-\alpha$ and $N F-\kappa B$ analysis results: TNF- $\alpha$ and NF-kB levels in brain tissue of BT group were significantly higher compared to SG and RBT groups $(p<0.001)$. However, the difference between TNF- $\alpha$ and NF-KB levels in the RBT and $\mathrm{SG}$ groups was not statistically significant (Figure 2).
Histopathological findings. Histopathological examination showed normal histological architecture of the brain tissue in the sections of the control group. Neurons had normal oval soma shape and stained basophilic, centered euchromatic nuclei and prominent nucleoli. Glial cells, especially astrocytes were normal in shape and glial cells were located was also normal and dense in appearance (Figure 3). In the BT group, most of pyramidal neurons were 


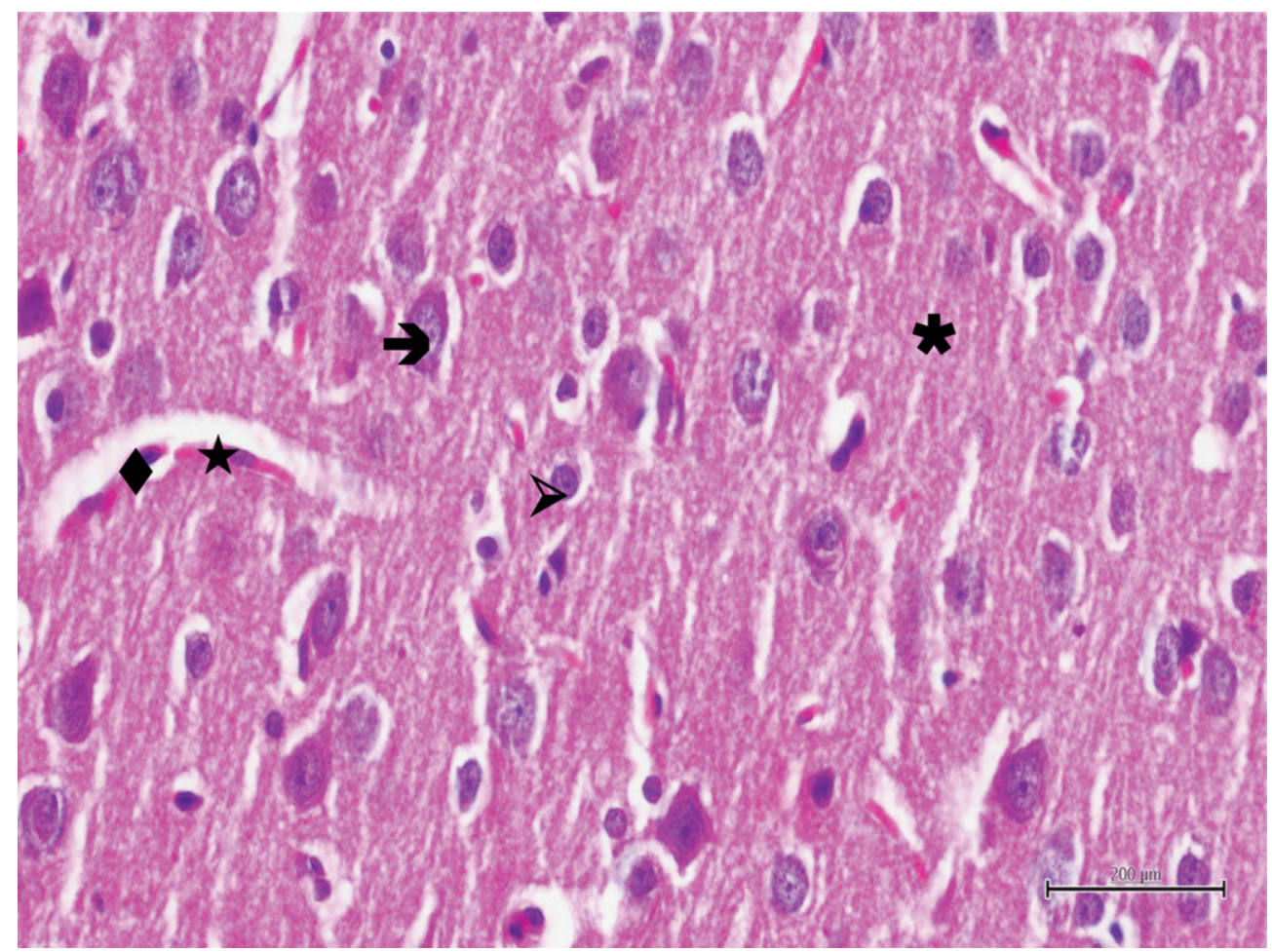

Figure 3. Hematoxylin-eosin staining in brain tissue in the control group; $\rightarrow$ : neuron, $>$ : astrocyte, $\star$ : blood vessel, $\bullet$ : endothelial cell, $\boldsymbol{*}$ : neuropile $\times 400$.

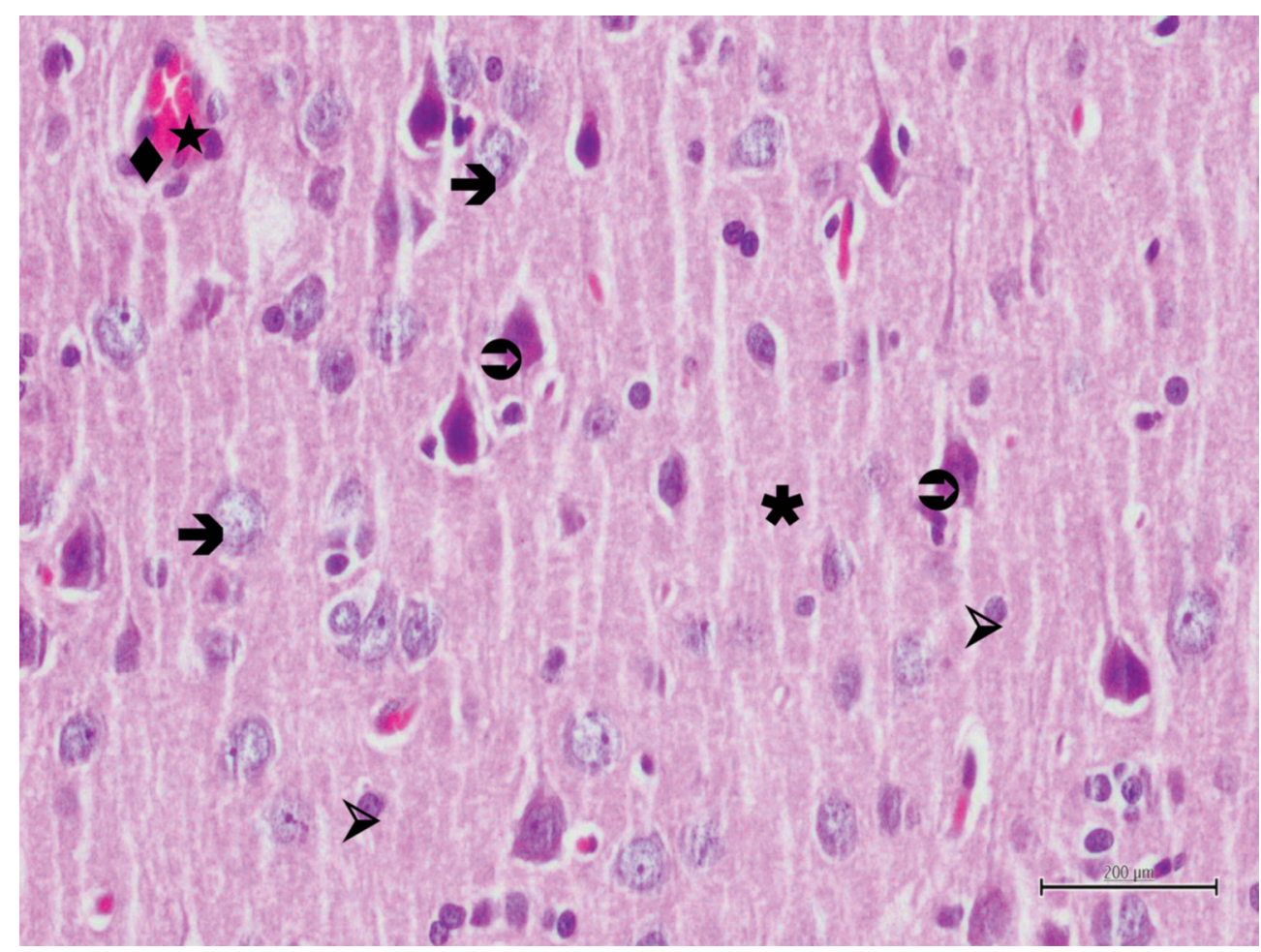

Figure 4. Hematoxylin-eosin staining of brain tissue in the experimental trauma group; $\rightarrow$ : edematous neuron, $\boldsymbol{\nabla}$ : degenerated neuron, $>:$ swollen astrocyte, $\star$ : dilated and congested blood vessel, $\downarrow$ : swollen endothelial cell, $*$ : vacuolized neuropile, $\times 400$. 


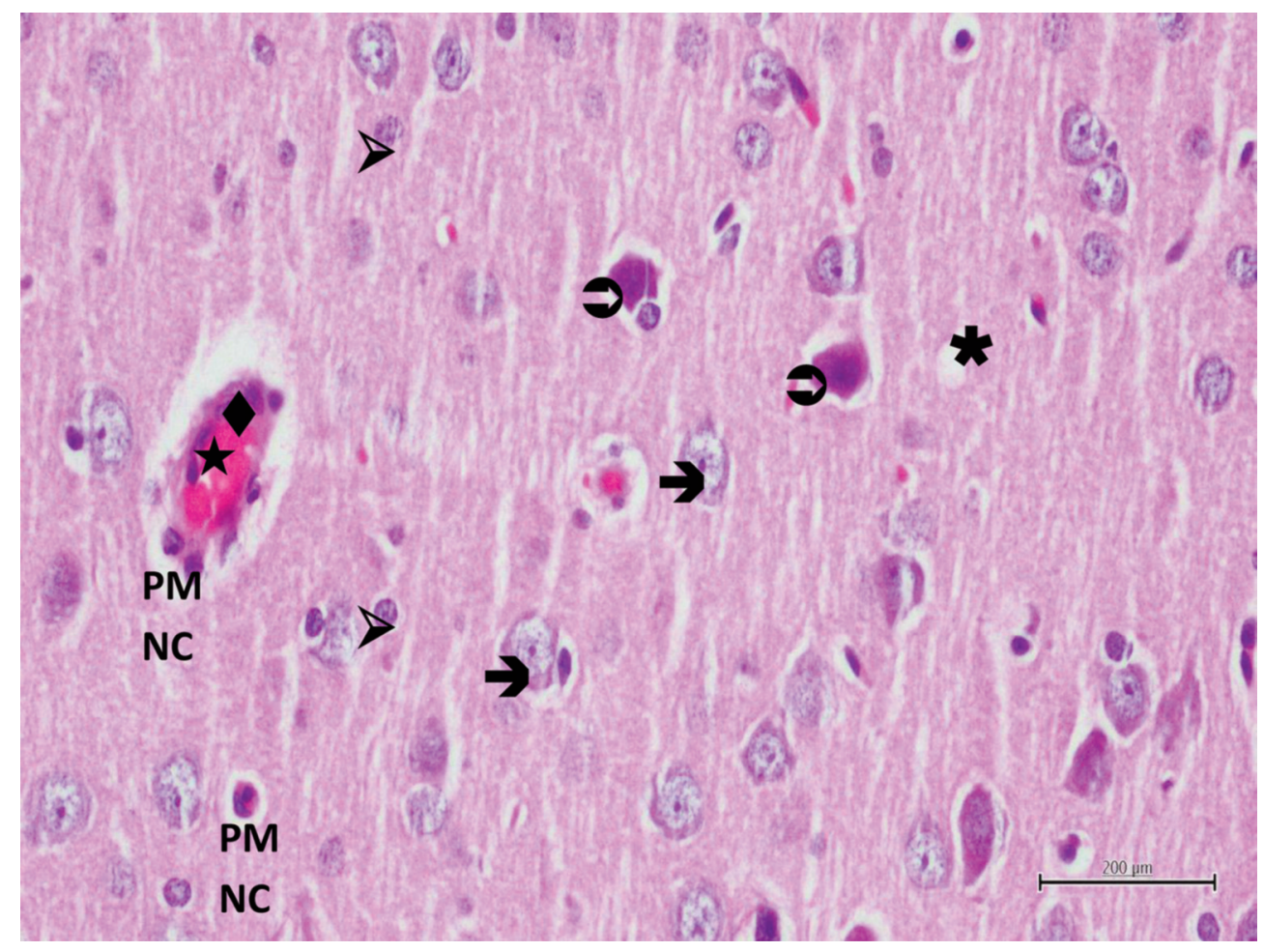

Figure 5. Hematoxylin-eosin staining of brain tissue in the experimental trauma group; $\rightarrow:$ edematous neuron, $\boldsymbol{\nabla}$ : degenerated neuron, $>:$ swollen astrocyte, $\star$ : dilated and congested blood vessel, $\downarrow$ : swollen endothelial cell, PMNC: polymorphonuclear cell, $*$ : vacuolized neuropile, $\times 400$.

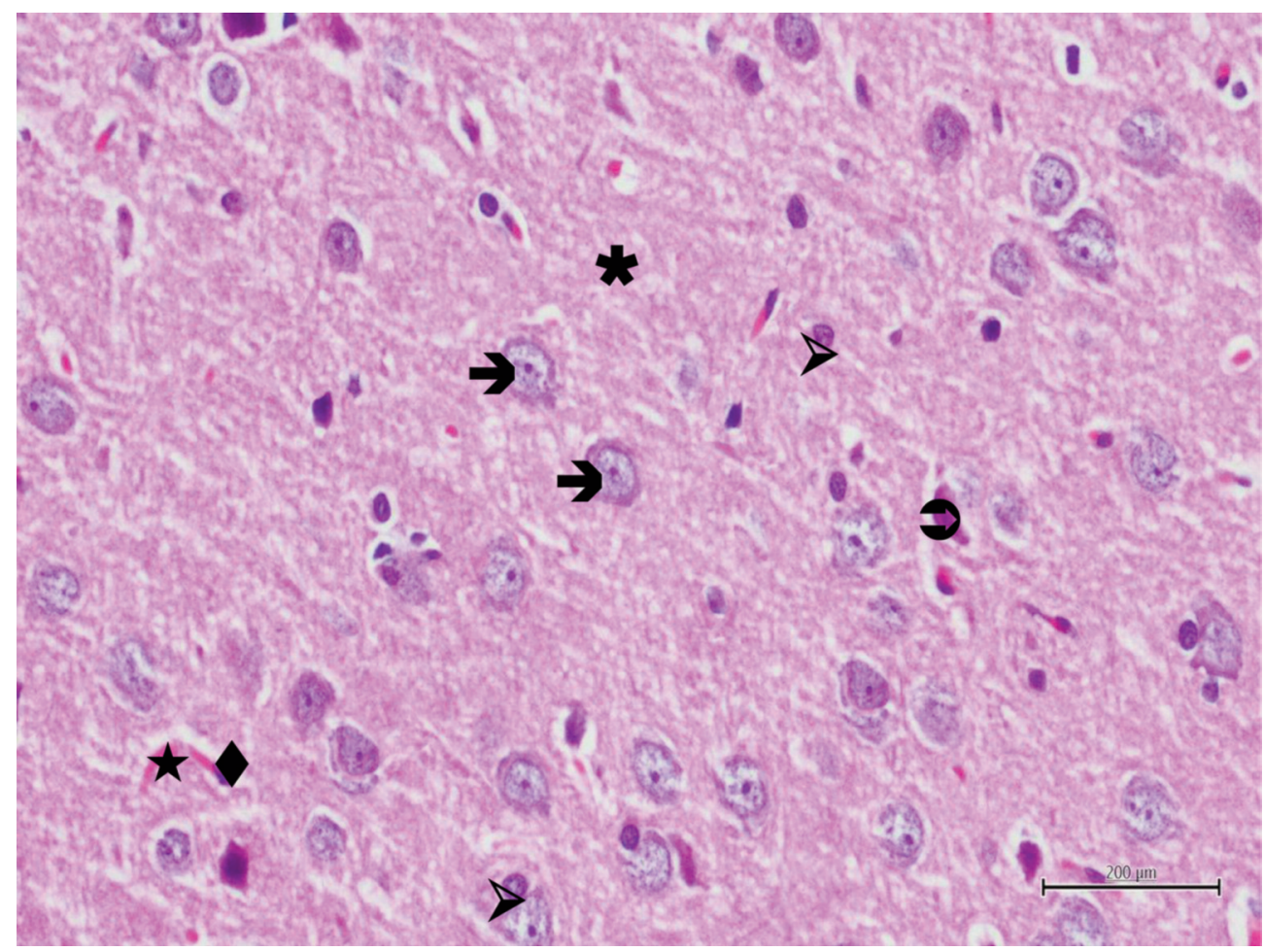

Figure 6. Hematoxylin-eosin staining of brain tissue in the rutin applied group after the experimental trauma; $\rightarrow$ : neuron, $\boldsymbol{\vartheta}:$ degenerated neuron, $>$ : astrocyte, $\star$ : blood vessel, $\downarrow$ : endothelial cell, $*$ : neuropile, $\times 400$. 
irregular in shape and had dark stained nuclei. Other neurons had pericellular halos and their nuclei had lost euchromatic appearance and their nucleoli had become subtle. Neuron blebbing and edema were also observed. Some neurons were degenerated and in the process of apoptosis. These findings were accompained by activation of astrocytes. Astrocytes had pericellular halos and the surrounding neuropile was intensely vacuolized. The blood vessels were dilated and congested and, in addition, endothelial cells were swollen (Figure 4). In some blood vessels polymorphonuclear cells were remarkable (Figure 5). In RBT group, neurons were generally normal in shape, they had euchromatic nuclei and clear nucleoli. However, pyramidal neurons still degenerated. Blood vessels, endothelial cells and astrocytes were normal in shape but the surrounding neuropile was still vacuolized in some regions (Figure 6).

\section{Discussion}

Primary TBI occurs immediately after impact. Secondary TBI occurs a few seconds after the first injury. The secondary phase is characterized by neuroinflammation, oxidative stress, and increased intracranial pressure due to brain edema (7). In this study, the effect of rutin on the secondary phase of TBI was evaluated. Treatment of head trauma usually aims at preventing secondary damage; prevention of secondary brain injury significantly reduces morbidity and mortality (16). Identification of novel therapeutic targets for the treatment of cellular injury would be beneficial to eliminate or reduce disability from nervous system trauma (17).

Head trauma has been shown to result in subsequent neurotrauma as a result of elevations in nervous system oxidative stress and free radical levels (18). Our experimental results showed that the levels of MDA in untreated brain tissue following mechanical trauma was higher, whereas the levels of tGSH were lower compared to the healthy group and rutin administered group. These results demonstrate that the oxidant-antioxidant balance in untreated damaged brain tissue is disrupted in favor of oxidants. The results also indicate that ROS production in brain tissue is induced. It has been shown that ROSs oxidize cell membrane lipids and produce toxic products such as MDA, which is in agreement with our biochemical findings. It has also been argued that oxidative damage occurs when the endogenous antioxidant system fails to neutralize excess ROS, which cause cellular damage (19). In our study, it was found that the oxidant-antioxidant balance was maintained in the brain tissue of animals that were treated with rutin following mechanical trauma. Rutin suppressed TBI-induced MDA increase and tGSH decrease. GSH is an endogenous antioxidant molecule that eliminates the harmful effects of radicals (20). Previous studies have also reported that MDA levels increase and those of tGSH decrease following TBI (21). It has been reported that rutin protects brain tissue cells from oxidative damage caused by increased MDA and decreased tGSH $(22,23)$.

In our study, mechanical trauma applied to the rat brain also caused an increase in the production of proinflammatory cytokines such as TNF- $\alpha$ and NF-kB. However, rutin suppressed the increase of TNF- $\alpha$ and NF$\mathrm{kB}$ in TBI. TNF- $\alpha$, and NF-kB have been documented to be cytokines responsible for the inflammatory process of secondary TBI injury $(24,25)$. Gugliandolo et al. have shown that TNF- $\alpha$ and NF-kB production increased following $\mathrm{TBI}$, and also injury regressed in brain tissue where TNF- $\alpha$ and NF-kB production was suppressed (26). There are no studies showing that rutin inhibits the overproduction of TNF- $\alpha$ and $\mathrm{NF}-\mathrm{kB}$ in damaged brain tissue. However, there are studies reporting that the antiinflammatory effect of routine is associated with proinflammatory cytokine inhibition (27).

The results of our biochemical experiments were consistent with the histopathological findings. There was marked dilated and conjunctival blood vessels, polymorphonuclear leukocyte (PMNL) accumulation, hemorrhage, and edema in traumatic brain tissue where oxidative stress and proinflammatory markers were increased. Degeneration, apoptosis, euchromatic nuclei, and pericellular halos were observed in pyramidal and other neurons. Halos and swelling were also detected in astrocytes. It has also been reported that secondary injury due to brain trauma is characterized neuroflamation, oxidative stress and increased brain edema (7). The role of $\mathrm{NF}-\mathrm{kB}$ in the development of trauma-related brain edema has been reported (9). Rutin administration reduced pyramidal neuron degeneration and PMNL accumulation due to brain tissue trauma, while eliminated edema and other histopathological symptoms. Previous studies have reported that rutin suppresses proinflammatory TNF- $\alpha$ and NF- $\mathrm{kB}$ production (12). Also, Moutinho et al. reported that rutin reduced cyclo-oxygenase- 2 expression in the dermis and tumor-associated inflammation in HPV16-induced lesions on mice (28). It has also been reported that rutin prevents edema developing as a result of increased capillary permeability and plasma leakage into the tissue (11). In addition, it has been shown that rutin prevents PMNL adhesion and migration and maintains vascular barrier integrity (12).

In conclusion, mechanical impact applied using an established method caused oxidative and proinflammatory damage in rat brain tissue. In addition, mechanical trauma caused significant brain edema. Rutin alleviated oxidative and proinflammatory brain damage and prevented brain injury. Therefore, rutin might be useful in the treatment of TBI and TBI-related edema. 


\section{Conflicts of Interest}

The Authors have no conflicts of interest to declare regarding this study.

\section{Authors' Contributions}

Sahin Yuceli: Study Design, data collection, writing manuscript; Gulce Naz Yazici: Histological examinations, data analysis; Renad Mammadov: Experimental procedure, data collection; Halis Suleyman: Experimental procedure, data collection, statistical analyses; Mustafa Kaya: Statistical analysis, writing manuscript; Selcuk Ozdogan: Data analyses, writing manuscript, final revisions.

\section{References}

1 Kim JM, Kim SC, Lee KH, Kim HJ, Kim H, Lee SW, Na DS and Park JS: Preventive effects of seat belts on traumatic brain injury in motor vehicle collisions classified by crash severities and collision directions. Eur J Trauma Emerg Surg, 2019. PMID: 30798345. DOI: 10.1007/s00068-019-01095-4

2 Coronado VG, Haileyesus T, Cheng TA, Bell JM, HaarbauerKrupa J, Lionbarger MR, Flores-Herrera J and McGuire LC: Gilchrist trends in sports- and recreation-related traumatic brain 1njuries treated in US Emergency Departments: The National Electronic Injury Surveillance System-All Injury Program (NEISS-AIP) 2001-2012. J Head Trauma Rehabil 30(3): 185197, 2005. PMID: 25955705. DOI: 10.1097/HTR. 0000000000000156

3 Dewan, MC, Rattani A, Gupta S, Baticulon RE, Hung YC, Punchak M, Agrawal A, Adeleye AO, Shrime MG and Rubiano AM: Estimating the global incidence of traumatic brain injury. J Neurosurg 1: 1-18, 2018. PMID: 29701556. DOI: 10.3171/ 2017.10.JNS17352

4 Yattoo $G$ and Tabish A: The profile of head injuries and traumatic brain injury deaths in Kashmir. J Trauma Manag Outcomes 2(1): 5, 2008. PMID: 18570674. DOI: 10.1186/17522897-2-5

5 Andriessen TM, Jacobs B and Vos PE: Clinical characteristics and pathophysiological mechanisms of focal and diffuse traumatic brain injury. J Cell Mol Med 14: 2381-2392, 2010. PMID: 20738443. DOI: 10.1111/j.1582-4934.2010.01164.x

6 Abdul-Muneer PM, Chandra $\mathrm{N}$ and Haorah J: Interactions of oxidative stress and neurovascular inflammation in the pathogenesis of traumatic brain injury. Mol Neurobiol 51(3): 966-979, 2015. PMID: 24865512. DOI: 10.1007/s12035-014$8752-3$

7 Niu X, Zheng S, Liu H and Li S: Protective effects of taurine against inflammation, apoptosis, and oxidative stress in brain injury. Mol Med Rep 18(5): 4516-4522, 2018. PMID: 30221665. DOI: $10.3892 / \mathrm{mmr} .2018 .9465$

8 Kaltschmidt B, Widera D and Kaltschmidt C: Signaling via NFkappaB in the nervous system. Biochim Biophys Acta 1745: 287-299, 2005. PMID: 15993497. DOI: 10.1016/j.bbamcr. 2005.05.009

9 Xiao G and Wei J: Effects of $\beta$-Aescin on the expression of nuclear factor- $\mathrm{kB}$ and tumor necrosis factor- $\alpha$ after traumatic brain injury in rats. J Zhejiang Univ Sci B 6(1): 28-32, 2005. PMID: 15593388. DOI: 10.1631/jzus.2005.B0028
10 Harborne JB: Nature, distribution and function of plant flavonoids. Prog Clin Biol Res 213: 15-24, 1986. PMID: 3520585 .

11 Chen WM, Jin M and Wu W: Experimental study on inhibitory effect of rutin against platelet activation induced by platelet activating factor in rabbits. Zhongguo Zhong Xi Yi Jie $\mathrm{He} \mathrm{Za}$ Zhi 22(4): 283-285, 2002. PMID: 12584792.

12 Lee W, Ku SK and Bae JS: Barrier protective effects of rutin in LPS-induced inflammation in vitro and in vivo. Food Chem Toxicol 50(9): 3048-3055, 2012. PMID: 22721984. DOI: $0.1016 /$ j.fct.2012.06.013

13 Ucar T, Tanriover G, Gurer I, Onal MZ and Kazan S: Modified experimental mild traumatic brain injury model. J Trauma $60(3)$ : 558-565, 2006. PMID: 16531854. DOI: 10.1097/01.ta. $0000209172.75637 . \mathrm{db}$

14 Ohkawa H, Ohishi N and Yagi K: Assay for lipid peroxides in animal tissues by thiobarbituric acid reaction. Anal Biochem 95: 351-358, 1979. PMID: 36810. DOI: 10.1016/00032697(79)90738-3

15 Sedlak J and Lindsay RH: Estimation of total, protein-bound, and nonprotein sulfhydryl groups in tissue with Ellman's reagent. Anal Biochem 25: 192-205, 1968. PMID: 4973948. DOI: 10.1016/0003-2697(68)90092-4

16 Korkmaz Dilmen O, Akçıl EF and Tunalı Y: intensive care treatment in traumatic brain injury. Turk J Anaesth Reanim 43: 1-6, 2015. DOI: 10.5152/TJAR.2014.26680

17 Chong ZZ, Li F and Maiese K: Oxidative stress in the brain: novel cellular targets that govern survival during neurodegenerative disease. Prog Neurobiol 75: 207-246, 2005. PMID: 15882775. DOI: 10.1016/j.pneurobio.2005.02.004

18 Cernak I, Savic VJ, Kotur J, Prokic V, Veljovic M and Grbovic D: Characterization of plasma magnesium concentration and oxidative stress following graded traumatic brain injury in humans. J Neurotrauma 17: 53-68, 2000. PMID: 10674758. DOI: $10.1089 /$ neu.2000.17.53

19 Suleyman H, Gül V and Erhan E: Oxidative stress and tissue damage. Erzincan Med J 1: 1, 2018.

20 Urso ML and Clarkson PM: Oxidative stress, exercise, and antioxidant supplementation. Toxicology 189: 41-54, 2003. PMID: 12821281. DOI: 10.1016/s0300-483x(03)00151-3

21 Zou P, Liu X, Li G and Wang Y: Resveratrol pretreatment attenuates traumatic brain injury in rats by suppressing NLRP3 inflammasome activation via SIRT1. Mol Med Rep 17(2): 3212-3217, 2018. PMID: 29257276. DOI: $10.3892 / \mathrm{mmr} .2017 .8241$

22 Zhai X, Ding Y, Wang Q, Zhang H and Li F: Rutin acid ameliorates neural apoptosis induced by traumatic brain injury via mitochondrial pathways in mice. Neuroimmunomodulation 23(3): 179-187, 2016. PMID: 27644033. DOI: 10.1159/ 000448716

23 Khan MM, Ahmad A, Ishrat T, Khuwaja G, Srivastawa P, Khan MB, Raza SS, Javed H, Vaibhav K, Khan A and Islam F: Rutin protects the neural damage induced by transient focal ischemia in rats. Brain Res 1292: 123-135, 2009. PMID: 19631195. DOI: 10.1016/j.brainres.2009.07.026

24 Batsaikhan B, Wang JY, Scerba MT, Tweedie D, Greig NH, Miller JP, Hoffer BJ, Lin CT and Wang JY: Post-injury neuroprotective effects of the thalidomide analog 3,6'dithiothalidomide on traumatic brain injury. Int J Mol Sci 20(3): 502, 2019. PMID: 30682785. DOI: 10.3390/ijms20030502. 
$25 \mathrm{Hu}$ YC, Sun Q, Li W, Zhang DD, Ma B, Li S, Li WD, Zhou ML and Hang $\mathrm{CH}$ : Biphasic activation of nuclear factor kappa B and expression of p65 and c-Rel after traumatic brain injury in rats. Inflamm Res 63(2): 109-115, 2014. PMID: 24146067. DOI: 10.1007/s00011-013-0677-1

26 Gugliandolo E, D'Amico R, Cordaro M, Fusco R, Siracusa R, Crupi R, Impellizzeri D, Cuzzocrea $\mathrm{S}$ and Di Paola R: Neuroprotective effect of artesunate in experimental model of traumatic brain injury. Front Neurol 9: 590, 2018. PMID: 30108544. DOI: 10.3389/fneur.2018.00590

27 Nafees S, Rashid S, Ali N, Hasan SK and Sultana S: Rutin ameliorates cyclophosphamide induced oxidative stress and inflammation in Wistar rats: Role of NFKB/MAPK pathway. Chem Biol Interact 231: 98-107, 2015. PMID: 25753322. DOI: 10.1016/j.cbi.2015.02.021
28 Moutinho MSS, Aragao S, Carmo D, Casaca F, Silva S, Ribeiro J, Sousa H, Pires I, Queiroga F, Colaco B, Medeiros R, Oliviera PA, Lopes C, Bastos MMSM and Da Costa RMG: Curcumin and rutin down-regulate Cyclooxygenase-2 and reduce tumorassociated inflammation in HPV16-transgenic mice. Anticancer Res 38(3): 1461-1466, 2018. PMID: 29491072. DOI: 10.21873/ anticanres.12371

Received May 19, 2020

Revised June 12, 2020

Accepted June 16, 2020 